\title{
Contra-Rotating Open Rotor Tone Noise Prediction
}

\section{Ed Envia}

\section{Acoustics Branch}

NASA Glenn Research Center

Presented at the $20^{\text {th }}$ AIAA/CEAS Aeroac oustics Conference Atlanta - J une 18, 2014

This work has been funded by the NASA Fixed Wing Project

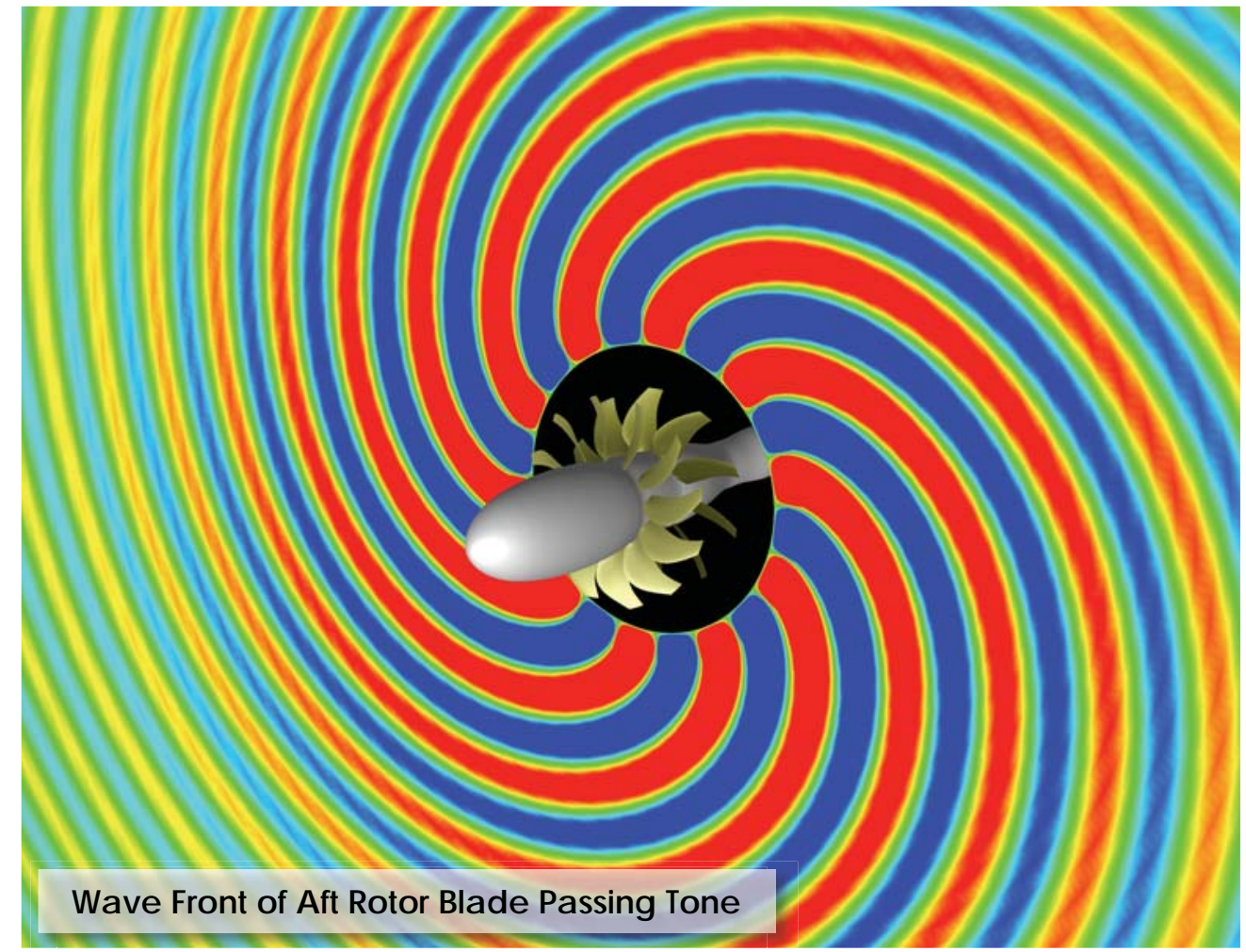




\section{Background}

* Changes in design paradigm have made possible contrarotating open rotor (CROR) propulsion systems that can retain their inherent fuel-effic iency advantage over turbofans while also be acoustically acceptable.
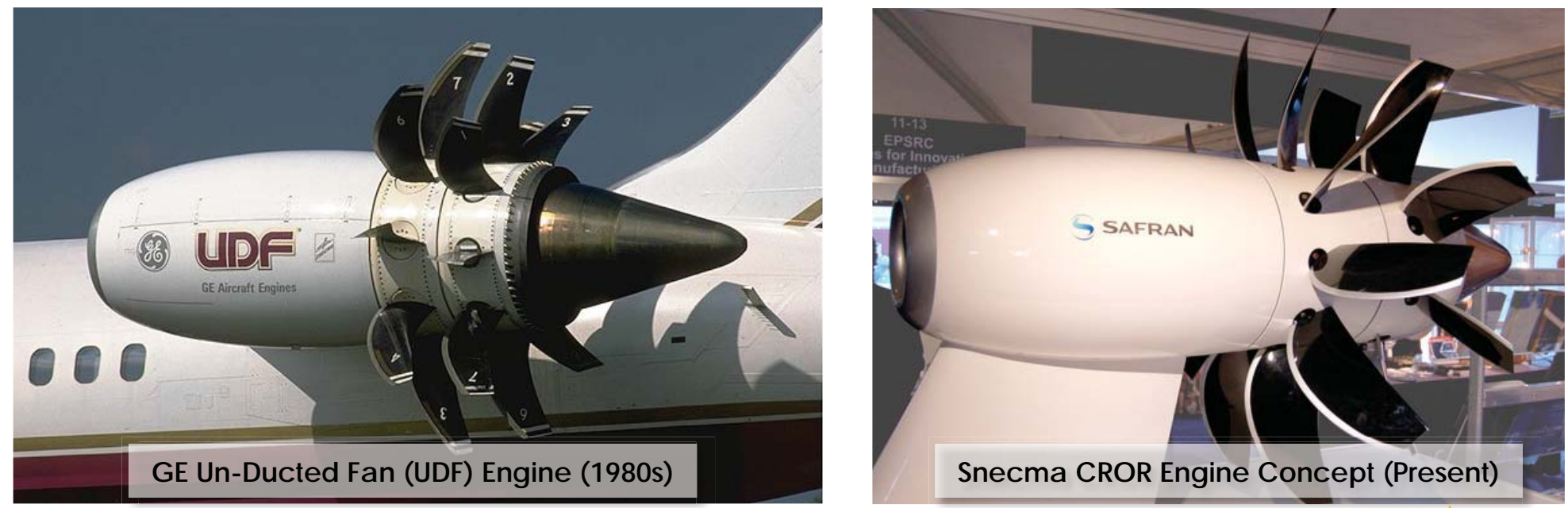

Lower tip speeds, increased rotor dia meters \& rotor-rotor spacing, unequal blade counts

\section{Shift in Design Philosophy}




\section{Motivation}

* Designing low-noise contra-rotating open rotor (CROR) propulsion systems that can meet both community noise regulations and cabin noise limits requires reliable aero/ acoustic prediction tools.

* Since CROR noise spectra exhibit a preponderance of tones, predicting their tone content has been the focus of many past and cument studies.

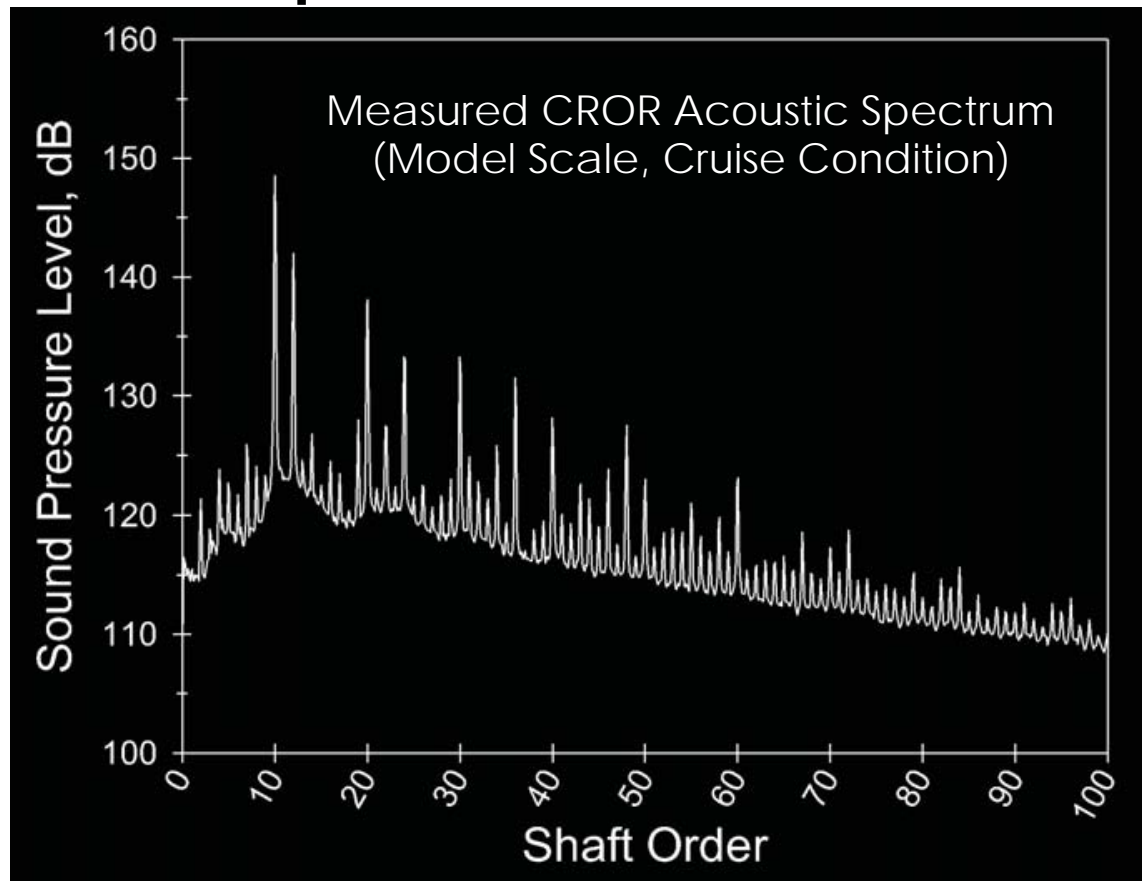

* In this study, a NASA open rotor tone noise model was assessed for its ability to predict CROR nearfield tone noise at cruise.

* The testbed is a benchmark GE model scale CROR blade set called F31/A31 for which extensive aero/acoustic data exist 


\section{AnAATHEN CROR Acoustic Modeling}

* Acoustic Analogy $\longrightarrow$ Frowcs Williams Hawkings Eq.

$$
p_{\text {acoustic }}^{\prime}=\int_{T} \rho_{S} v_{n} \frac{D_{0} G}{D \tau} d S d \tau+\int_{T}^{\text {Blade Nomal Velocity }} f_{S} f_{i} \frac{\partial G}{\partial y_{i}} d S d \tau+
$$

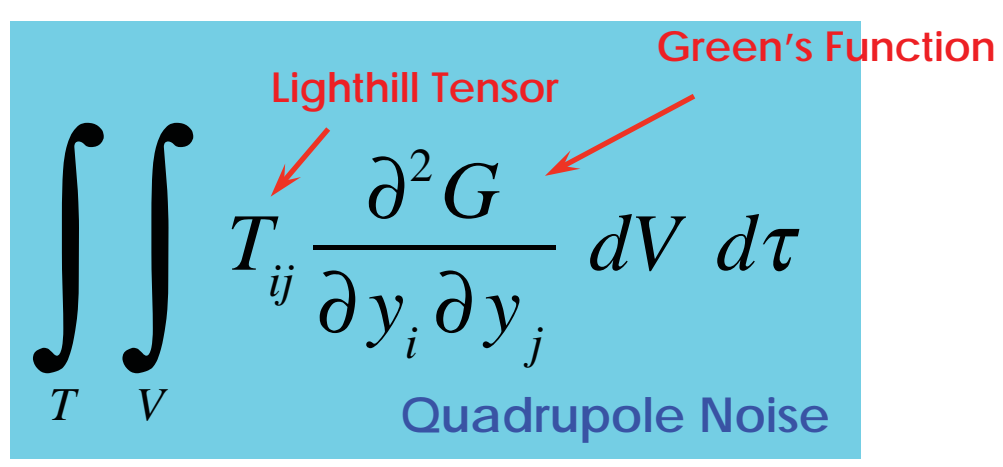

$$
f_{i}=-\left(p-p_{0}\right) n_{i}, \quad T_{i j}=\rho u_{i} u_{j}+\delta_{i j}\left[\left(p-p_{0}\right)-c_{0}^{2}\left(\rho-\rho_{0}\right)\right]
$$

Owing to the linea rity of the acoustic field, the a coustic contribution of each rotor can be calculated separately and the two contributions combined to estimate CROR noise field. 


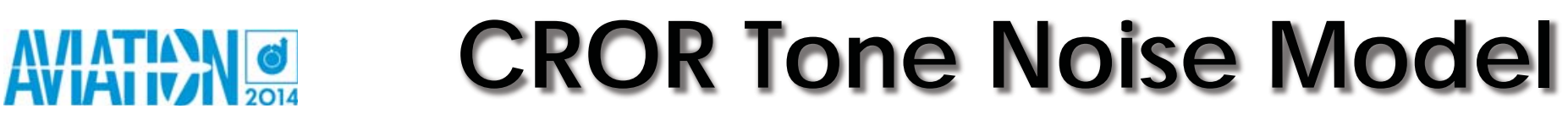

\section{* Tonal acoustic field for front rotor}

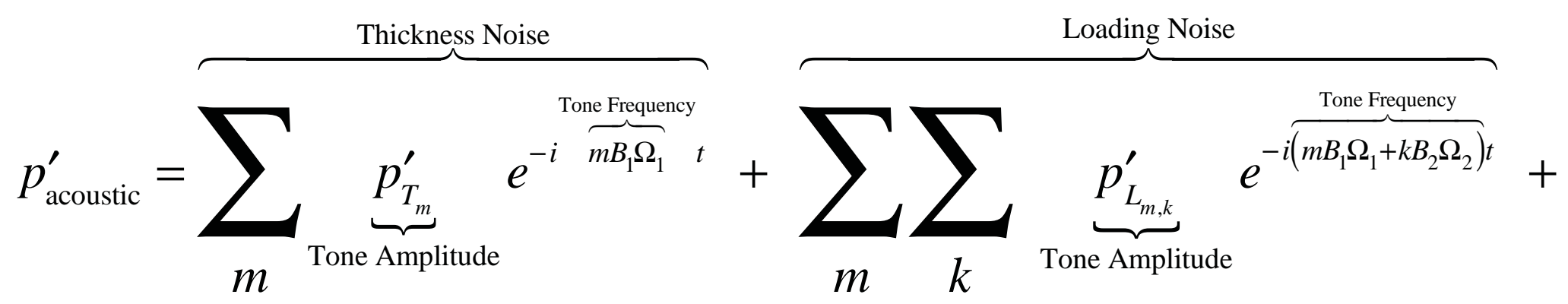

Quadrupole Noise

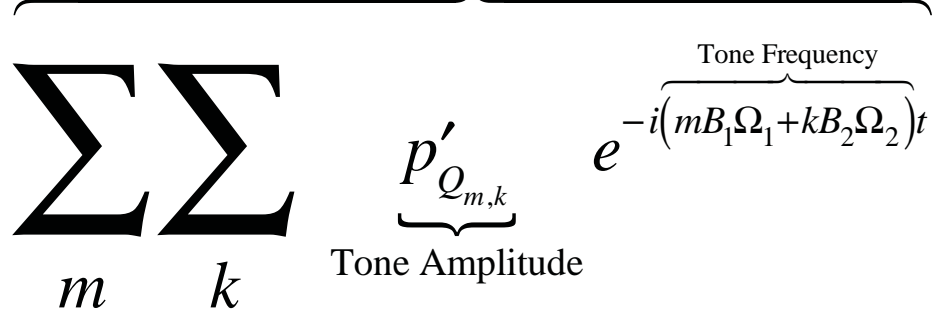

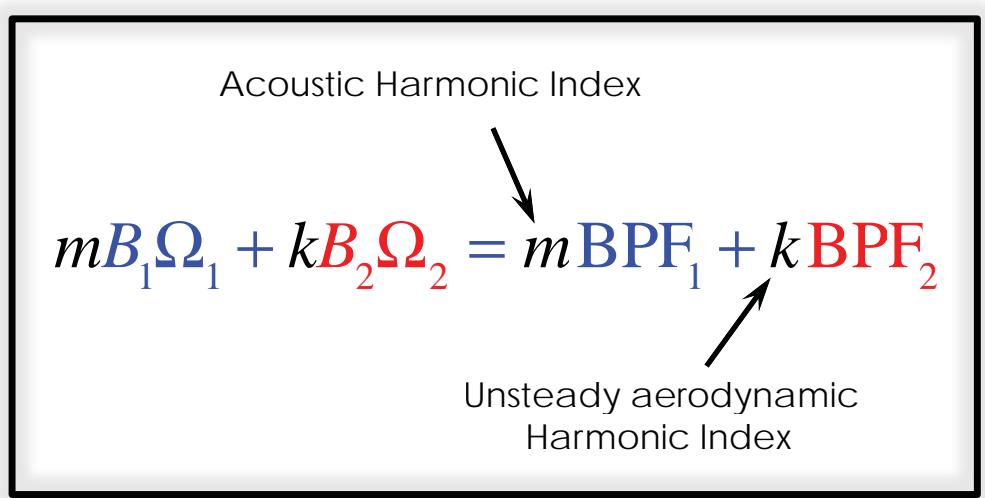

Thic kness noise is produced at the hamonic sof the blade passing frequency of each rotor. Loading noise and quadrupole noise are produced at the harmonics of the blade passing frequency of each rotor as well as at the sum and difference combinations of the front and aft rotorblade passing frequencies. 


\section{AVIATHWN CROR TOne Noise Model (Cont'd)}

* Tone amplitudes of various sources

$$
\begin{aligned}
& p_{T_{m}}^{\prime}=\int_{S}[\int_{0}^{2 \pi / \Omega_{1}} \underbrace{\rho_{0} v_{n}}_{\substack{\text { Thickness Source } \\
\text { (geomertic input) }}} \underbrace{\Theta_{T}(\tau)}_{\substack{\text { Source } \\
\text { Directivity }}} \underbrace{G(\tau)}_{\text {Propagation }} d \tau] d S \\
& \left.p_{L_{m, k}}^{\prime}=\int_{S}[\int_{0}^{2 \pi / \Omega_{1}} \underbrace{\underbrace{\Theta_{L_{i}}(\tau)}_{\substack{\text { Source } \\
\text { Directivity }}}}_{\substack{\text { Loading Souruce } \\
f_{\text {(arodynamic input }-C F D)}(\tau)}} \underbrace{G(\tau)}_{\text {Propagation }} d \tau] d S\right\} \text { LNPROP Code }
\end{aligned}
$$

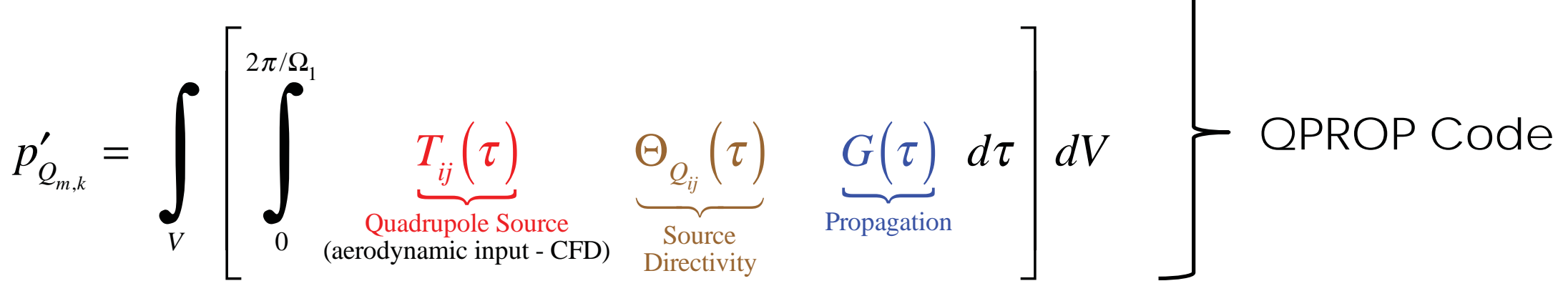

Asymptotic approximations to integrals over source time $T$ yield efficient formulas of computing $C$ ROR tone amplitudes. Replace $\left(B_{1} \& \Omega_{1}\right)$ w. $\left(B_{2} \& \Omega_{2}\right)$ for aft rotor tones. 


\section{Aerodynamic Input}

* Aerodynamic input for use in the acoustic model (i.e., blade loading and Lighthill tensor distributions) can be extracted or reconstructed from unsteady aerodynamic simulations.

* In this work commercial CFD software package RNE/Turbo"M was used to generate the required unsteady aerodynamic inputs.

* The nonlinear hamonic (NLH) approximation was used to significantly reduce unsteady aerodynamic simulation times.

* Means plus three harmonics of the unsteady flow were considered in this study. For the dense grid used:

- NUH CPU time 5-6 x steady state solution time

- Full unsteady CPU time $\sim 100$ x steady state solution time 


\section{ANATHAN Aerodynamic Input (Cont'd)}

* The NUH grid is comprised of 73 bloc ks and $27.1 \times 10^{6}$ mesh points. One passage each of the front and aft rotors plus ancillary regions like spinner, hub and farfield are included.

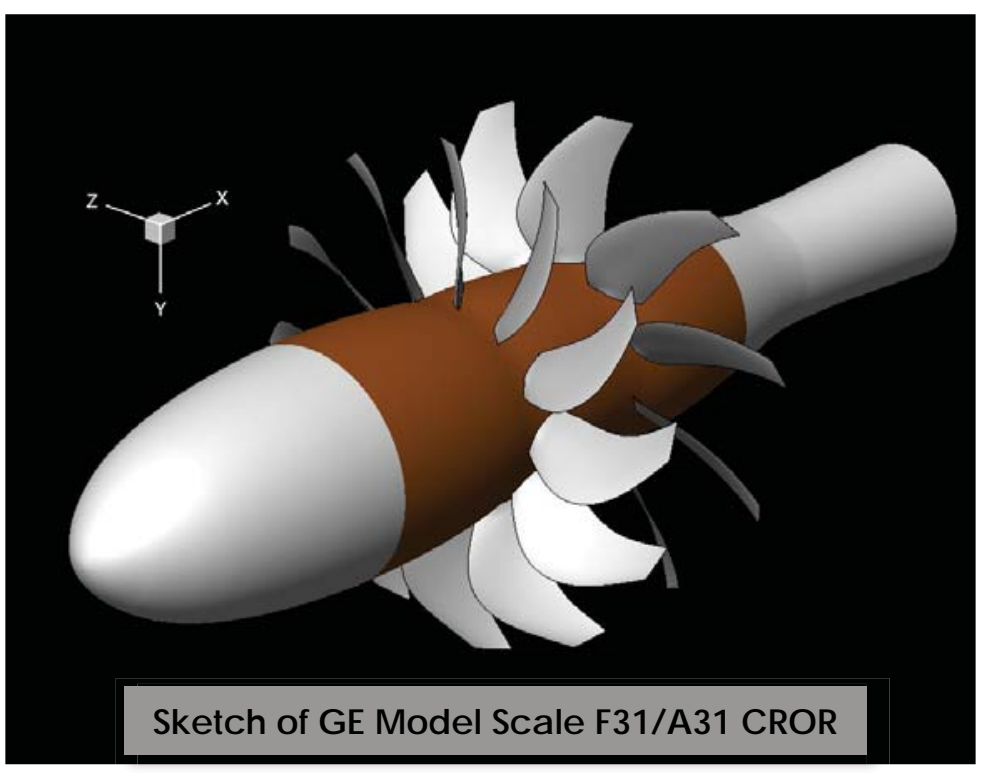

\begin{tabular}{|l|l|}
\hline Front Rotor Blade Count & 12 \\
\hline Aft Rotor Blade Count & 10 \\
\hline Front Rotor Diameter & $0.66 \mathrm{~m}$ \\
\hline Aft Rotor Diameter & $0.63 \mathrm{~m}$ \\
\hline Rotor-Rotor Spacing & $0.20 \mathrm{~m}$ \\
\hline
\end{tabular}

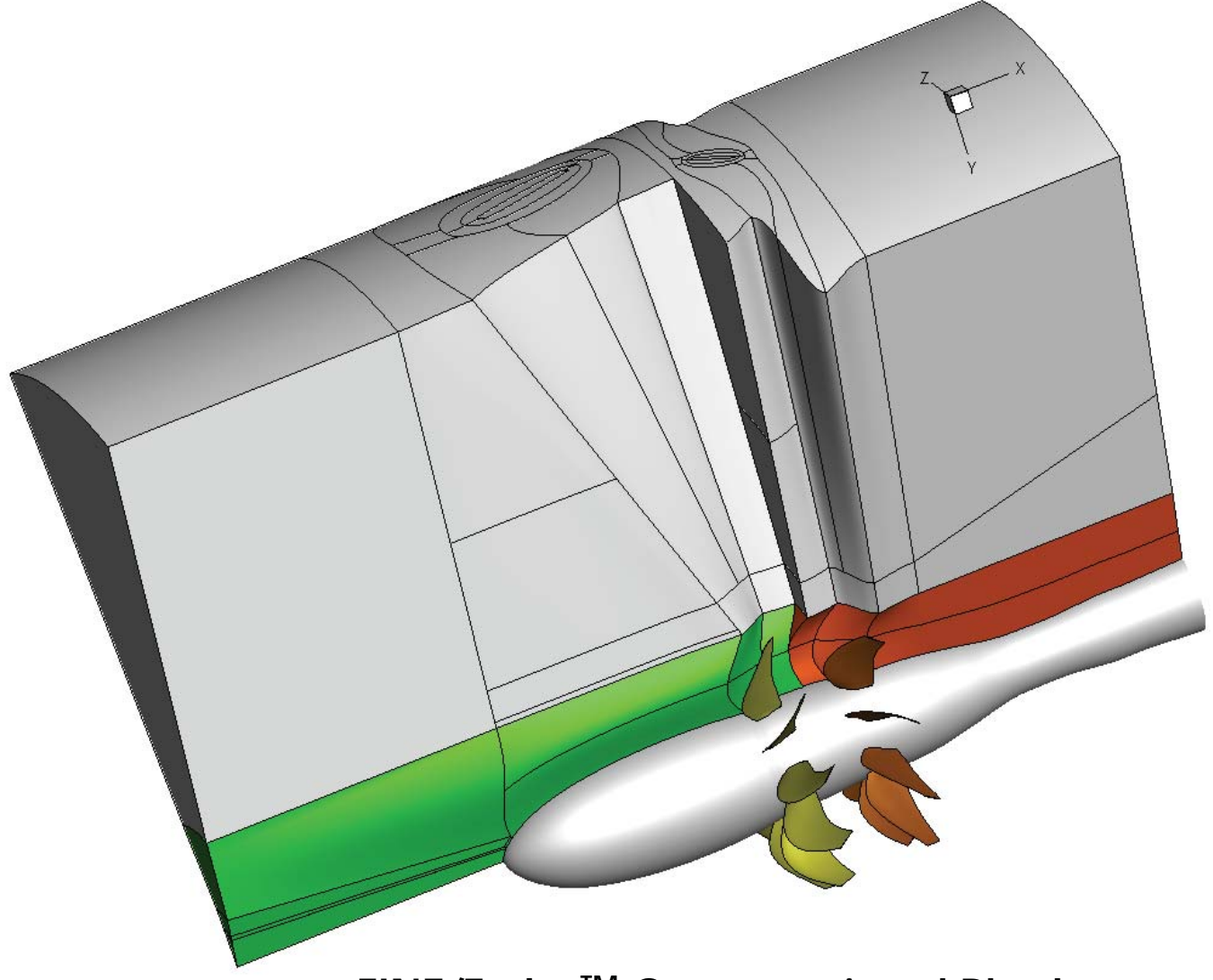

RNE/Turbo TM Computational Block (farfield blocks shown in gray) 
- Aerodynamic/Acoustic data used for comparisons in this study were acquired in the NASA 8' $\times 6^{\prime}$ ' high speed wind tunnel. Aerodynamic data include thrust and torque measurements, and acoustic data include nearfield sideline measurements.

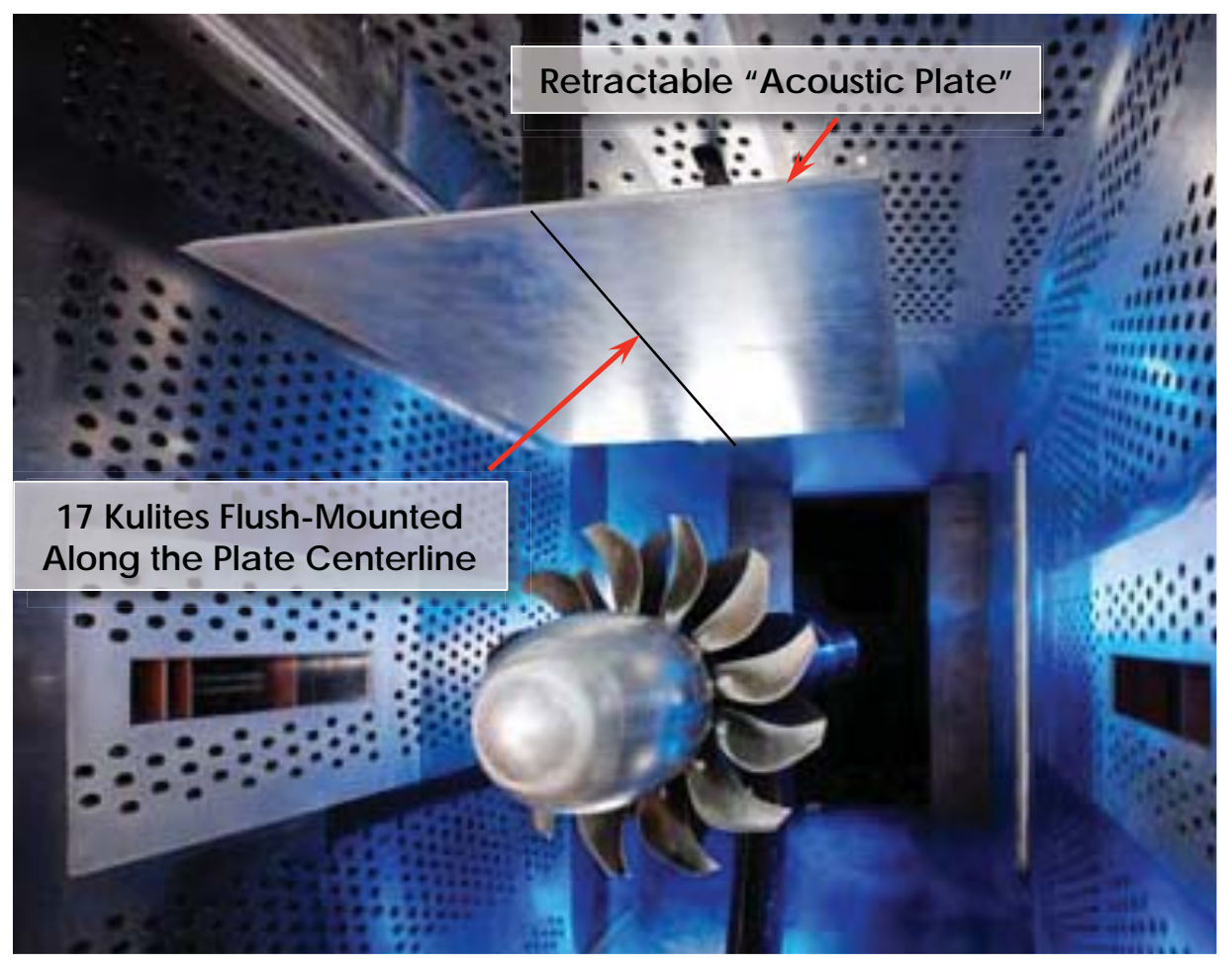

Model Scale GE F31/A31 Installed in NASA 8' × 6' WT

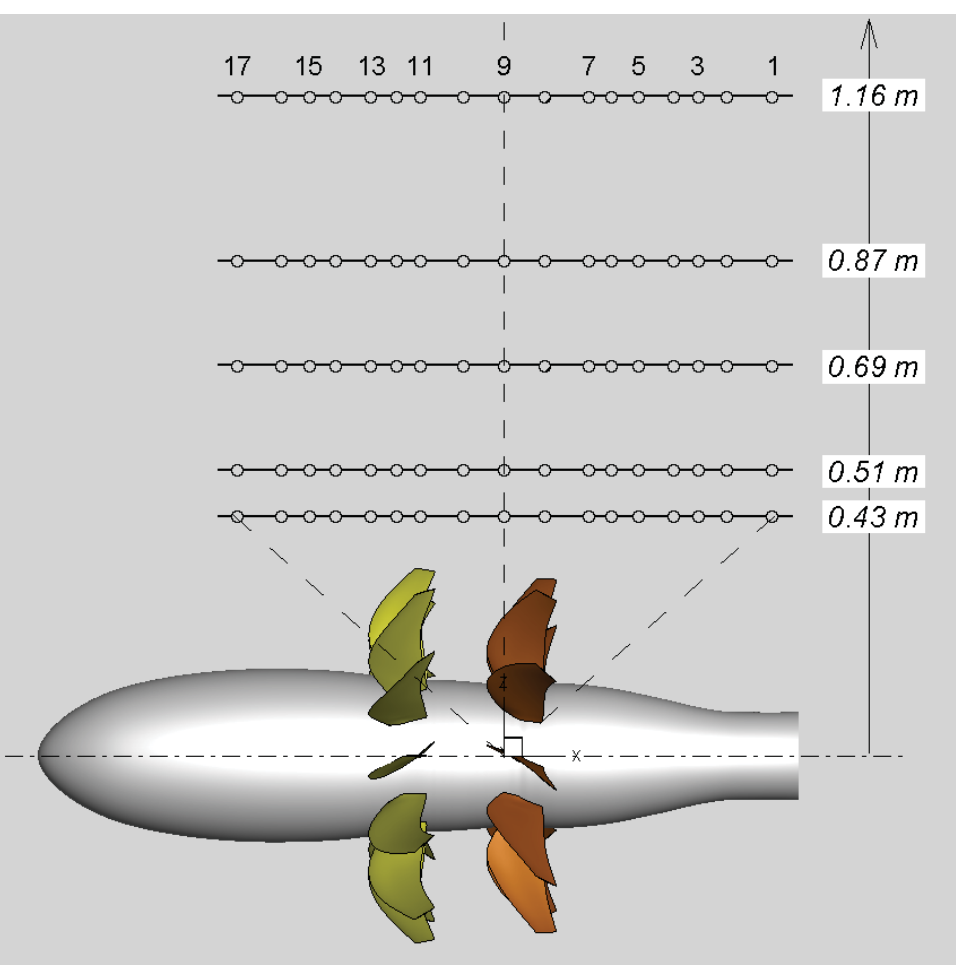

Vertical Positions of the Plate Relative to Open Rotor Axis 


\section{AfIATHEN Aerodynamic Predictions}

* In total eight tip speed conditions were simulated. The front and aft rotor speeds were equal for all cases though neither the aero nor the acoustic model is restric ted to equal RPM cases.

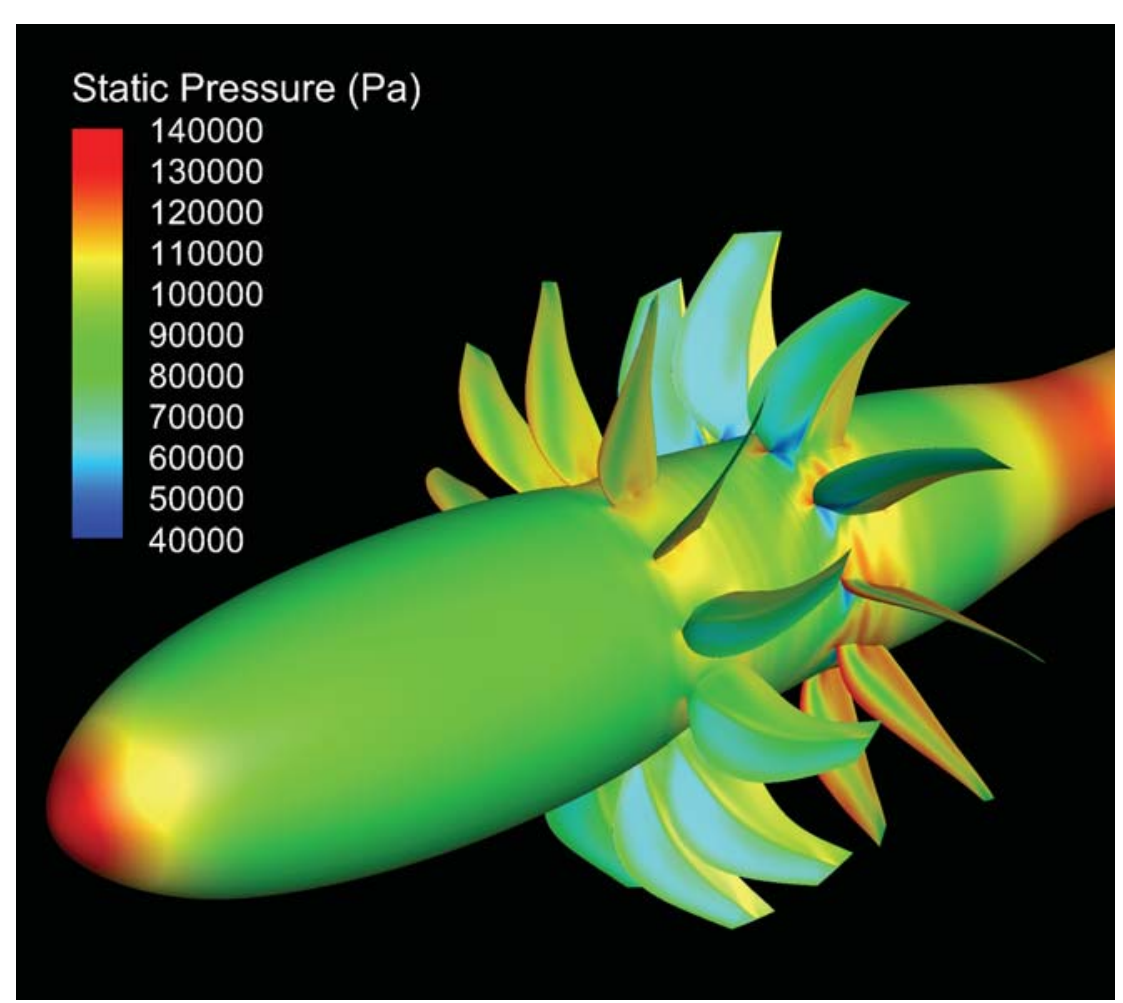

Mean Pressure Distribution at Highest Speed

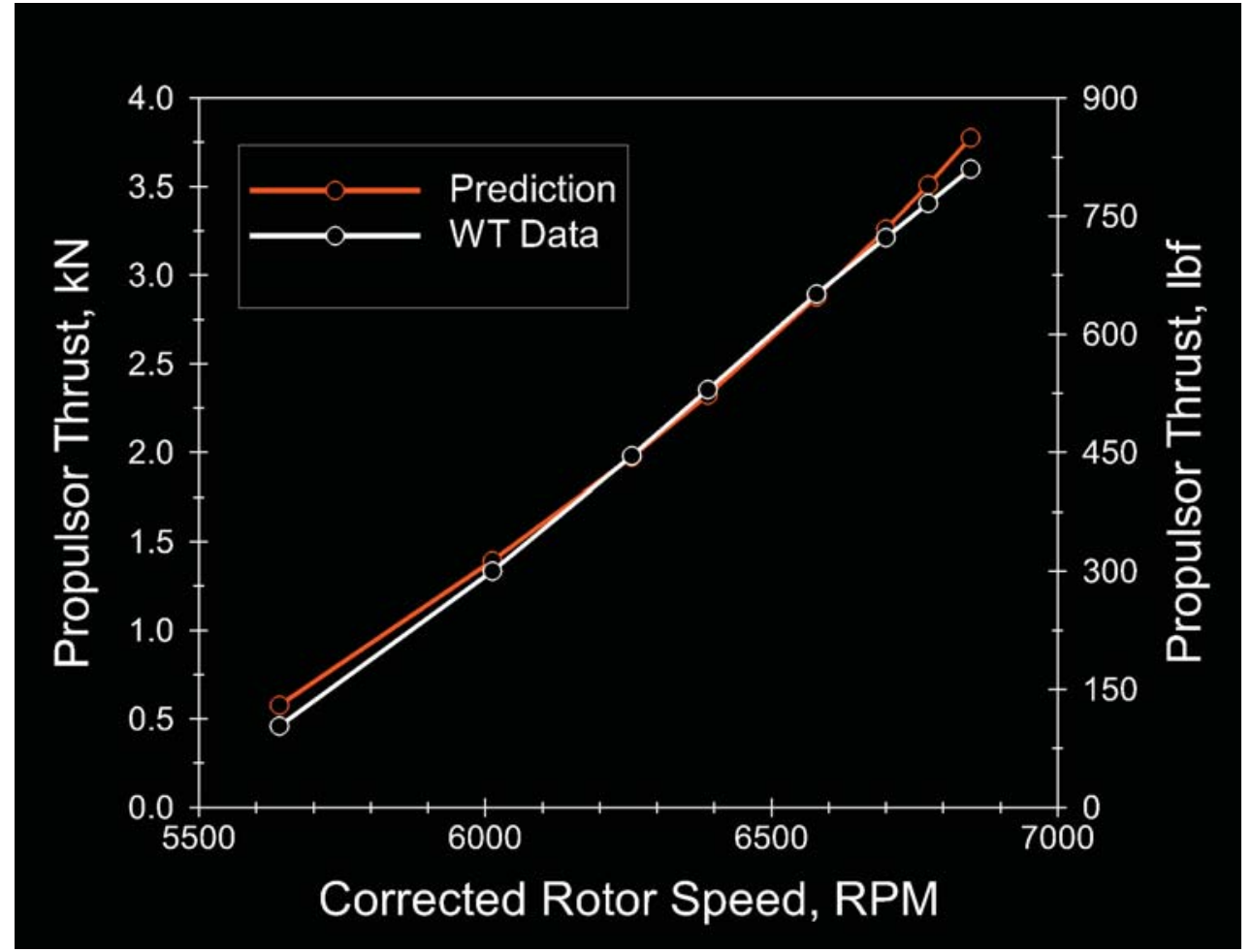

Predicted \& Measured Propulsor Thrust as a Function of Rotor Comected Speed 


\section{Acoustic Predictions}

* Tone spectral comparisons at the highest tip speed broadside to the aft rotor for farthest plate position.

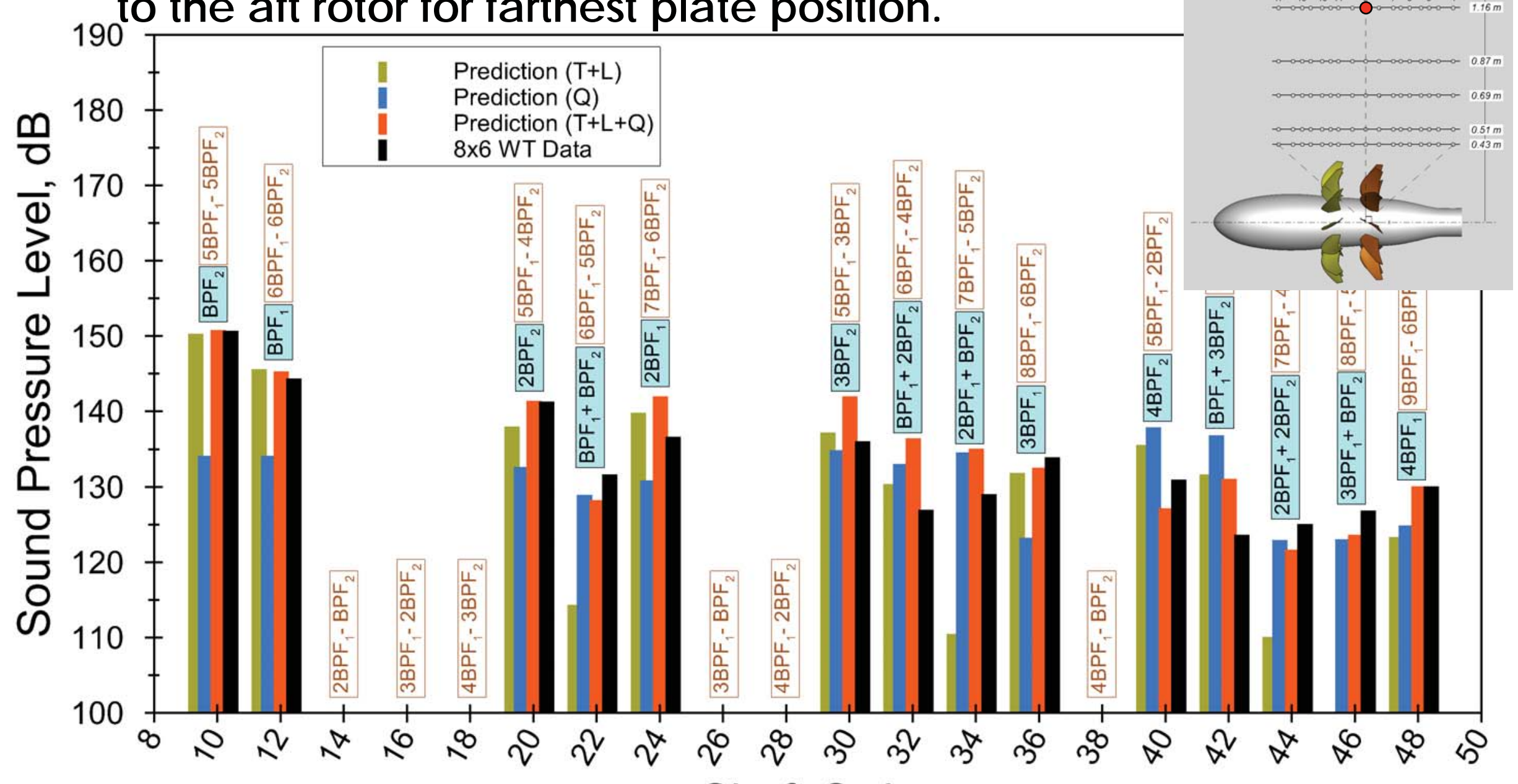

Shaft Order

Typic ally, rotor tones a re well-predic ted using thic kness \& loa ding sourc es only, but National Ae interaction tones require the inclusion of quadrupole source for betteragreement. 


\section{AllATHAN Acoustic Predictions (Cont'd)}

* Select tone SPLs at the highest tip speed broadside to the aft rotor for all plate positions.

Vertical Distance in Front Rotor Tip Radii

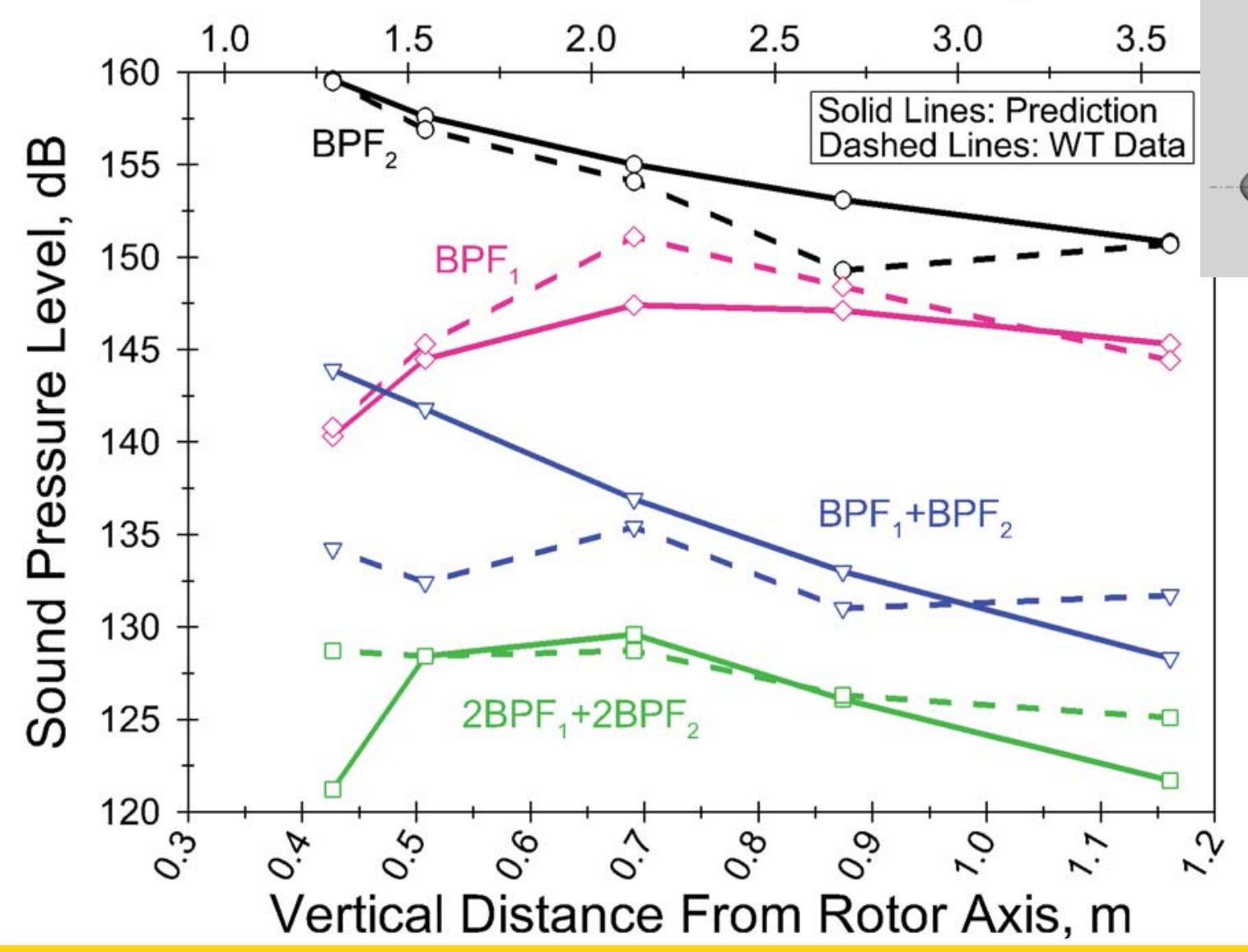

Absolute level of rotor tones are generally well-predicted (avg. Error $=1 \mathrm{~dB}$ ). The agreement for the interaction tones is fair (avg. Emor $\leq 3 \mathrm{~dB})$. 


\section{AlAATHWN: Acoustic Predictions (Cont'd)}

* Tone OASPL at the highest tip speed broadside to the aft rotor for all plate positions.

Vertical Distance in Front Rotor Tip Radii

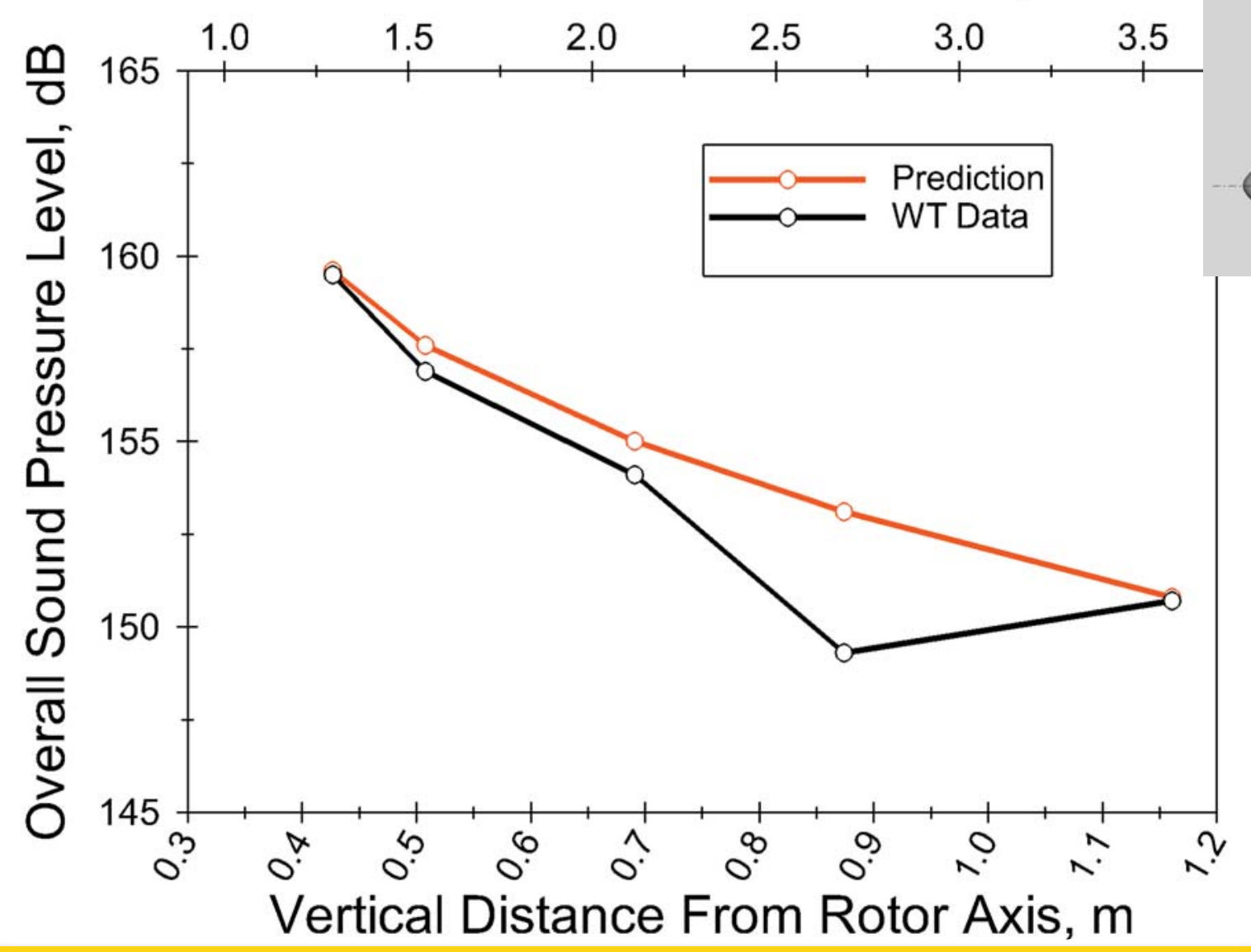

Tone OASPL is extremely well-predicted in all but one plate position. The National predicted trend with plate distance is less erratic than the measured trend. 


\section{AllAHILAN Acoustic Predictions (Cont'd)}

* Tone OASPL as a function of tip speed broadside to the aft rotor for two plate positions.

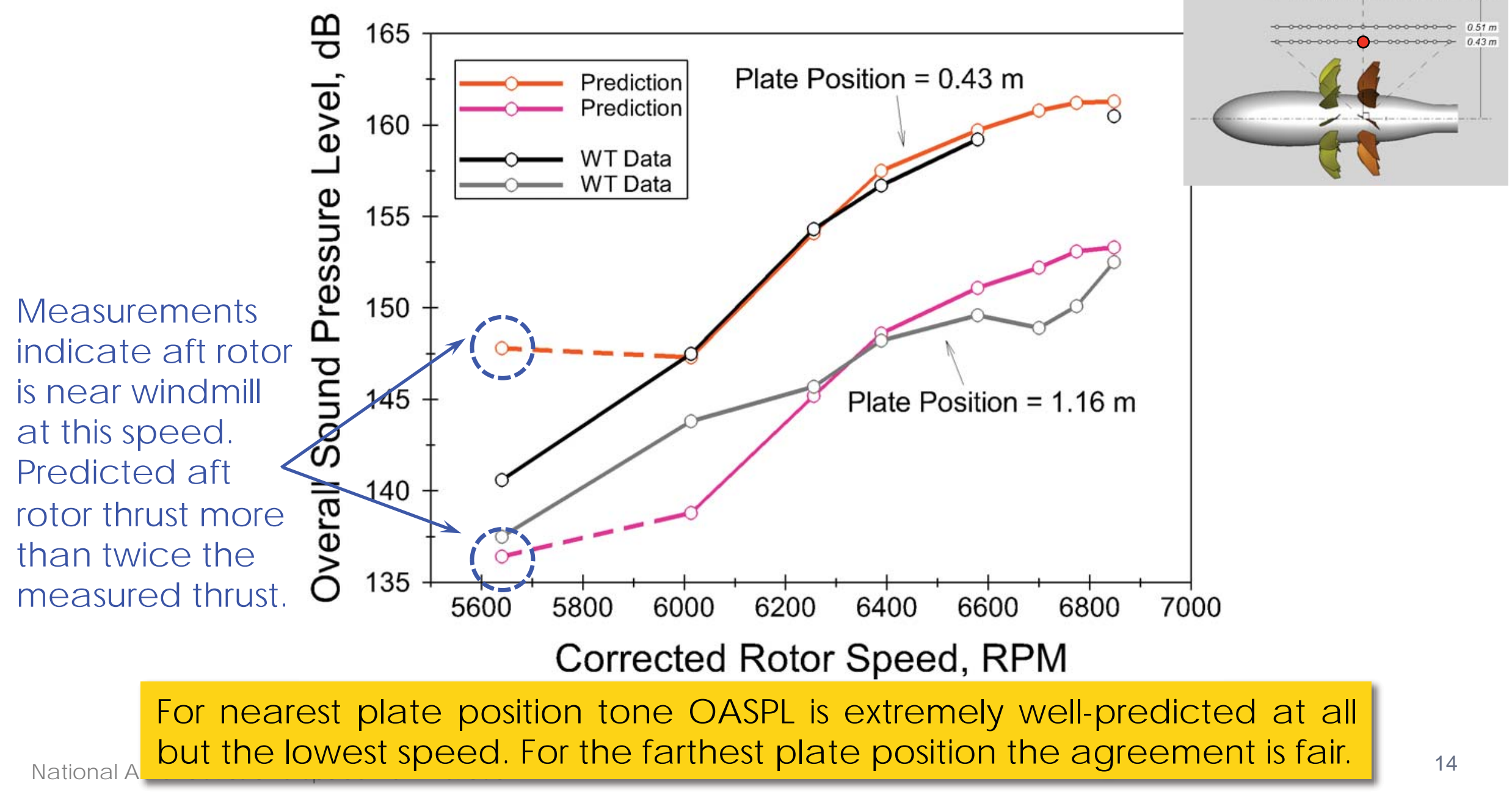




\section{AVAATHEN Acoustic Predictions (Cont'd)}

* Tone OASPL directivity for highest tip speed for nearest plate position.

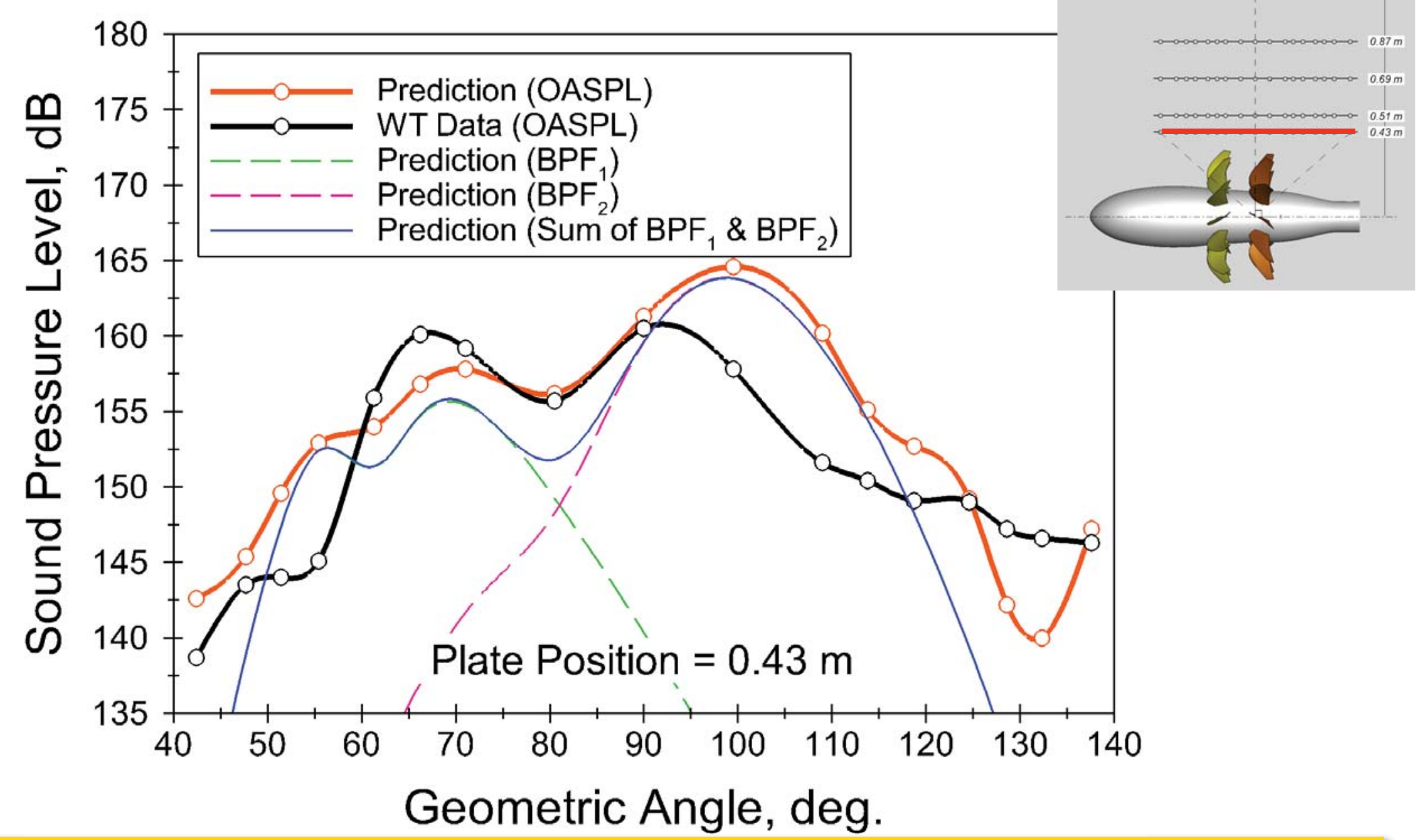

The data-theory agreement for the basic features and trends of tone OASPL directivity is good. In the neighborhood of the broadside location the levels are well-predicted. 


\section{AVAATHEN Acoustic Predictions (Cont'd)}

* Tone OASPL direc tivity for highest tip speed for farthest plate position.

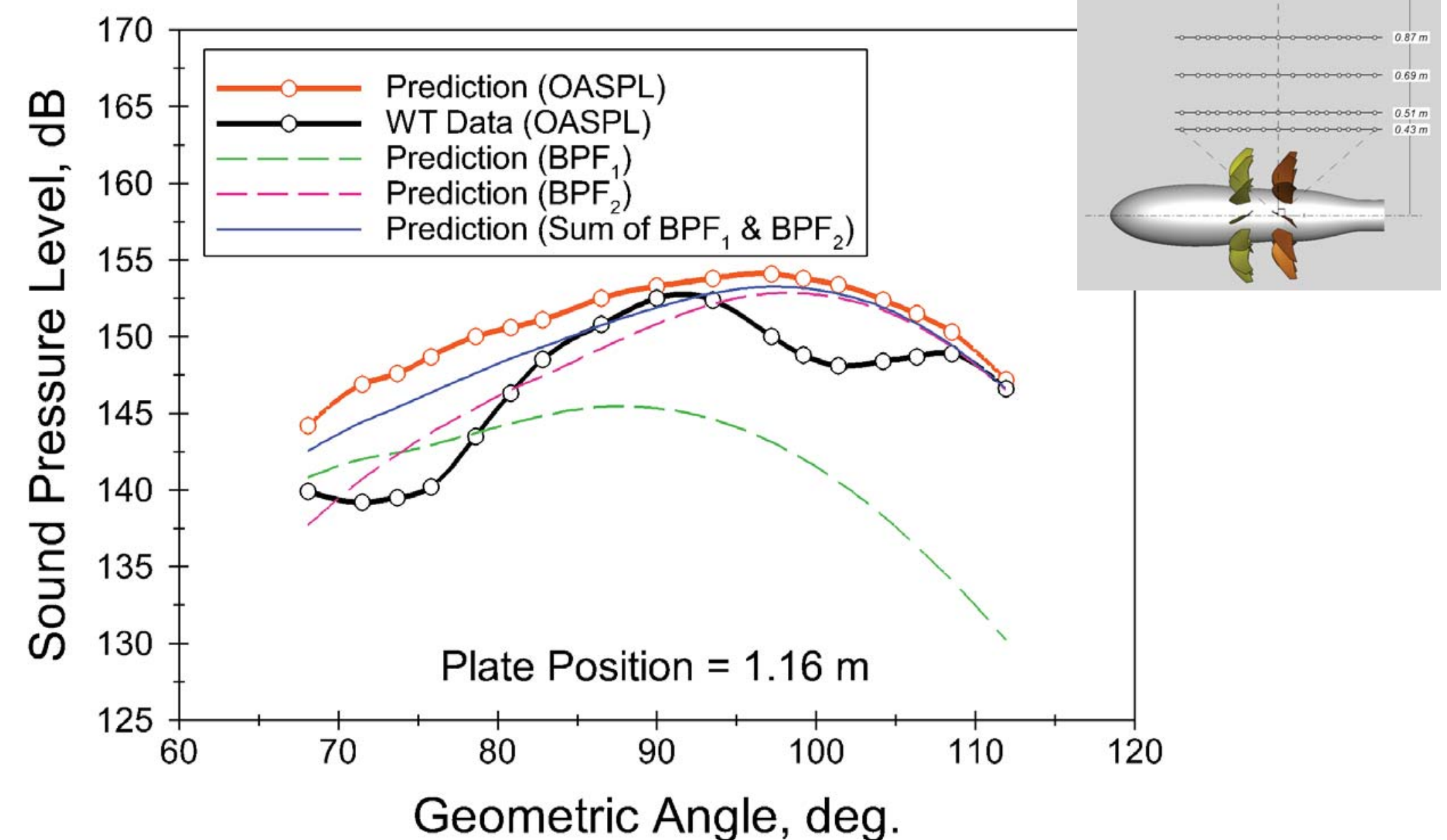

The data-theory agreement for the basic features and trends of tone OASPL directivity is fa ir. In the neighborhood of the broadside location the levels are well-predicted. 


\section{Summary}

* Assessment of a NASA acoustic analogy based open rotor noise predic tion model has been carried out using nearfield acoustic data acquired for a model scale open rotor at cruise condition.

- Comparisons indic ate that the strongest tones as well as tone OASPL are well predic ted for the broadside locations for which plate boundary layer and end-effect comections are relatively small.

* The quadrupole source does not influence the levels of rotor tones, but is crucial in determining the interaction tone levels.

* Not unexpectedly, the aft rotor contribution is more significant than the front rotor's.

* Thic kness and loading source levels contribute roughly equally for the front rotor tones, but for the aft rotor tones the loading noise is entirely dominant 


\section{Questions?}

